\title{
BETAMETHASONE DIPROPIONATE GEL FOR TREATMENT OF LOCALIZED PLAQUE PSORIASIS
}

\author{
SANAA EL-GIZAWAY1* ${ }^{*}$ MAHA FADEL ${ }^{2}$, BASMA MOURAD ${ }^{3}$, FATMA EL-ZAHRAA ABD ELNABY ${ }^{1}$
}

${ }^{1}$ Department of Pharmaceutical Technology, Faculty of Pharmacy, Tanta University, Egypt, ${ }^{2}$ Department of Medical Laser Application, National Institute of Laser Enhanced Sciences, Cairo University, Egypt, ${ }^{3}$ Department of Dermatology, Andrology and Venereology Diseases, Faculty of Medicine, Tanta University, Egypt

Email: selgizawy@hotmail.com

Received: 20 Mar 2017 Revised and Accepted: 30 Jun 2017

\section{ABSTRACT}

Objective: The main aim of this study was to design and characterise betamethasone di-propionate loaded transfersomes (BD-T); as a topical formulation for the treatment of localized plaque psoriasis.

Methods: A full factorial design $\left(2^{3}\right)$ was applied to study the effects of three independent variables: drug content, type of surfactants and surfactant contents on particle size (PS), entrapment efficiency (EE \%), zeta potential (ZP), polydispersity index (PI) and drug release profiles. The optimized BD-T was formulated as a hydrogel using 5\% sodium carboxymethyl cellulose. The gel was characterized for viscosity, drug content, in vitro drug release and stability. A comparative clinical study was performed on 20 patients with psoriasis to investigate the effect of BD-T gel and the marketed betamethasone dipropionate (BD) cream.

Results: The optimized BD-T formulation containing $50 \mathrm{mg}$ betamethasone dipropionate (BD) and $5 \mathrm{mg}$ tween 80 showed spherical unilamellar vesicles with an average particle size of $242.80, \% \mathrm{EE}$ of $90.19 \%$, ZP of- $15.00 \mathrm{mV}$, PI of 0.407 and $\mathrm{K}_{0}$ of $4.290 \mathrm{mg} / \mathrm{hr}$. The formulation showed good stability at $4{ }^{\circ} \mathrm{C}$ and $25{ }^{\circ} \mathrm{C}$ for 6 mo. The results revealed significant clinical improvement and a significant increase in safety and tolerability with BD-T gel compared with BD cream.

Conclusion: As a conclusion, BD-T was found to be more effective, safe and tolerable for the treatment of psoriasis compared with the marketed product.

Keywords: Transfersomes, Betamethasone dipropionate (BD), Localized psoriasis

(C) 2017 The Authors. Published by Innovare Academic Sciences Pvt Ltd. This is an open access article under the CC BY license (http://creativecommons.org/licenses/by/4.0/) DOI: http://dx.doi.org/10.22159/ijpps.2017v9i8.18571

\section{INTRODUCTION}

Psoriasis is a chronic inflammatory skin disease-with increased epidermal proliferation related to dysregulation of immune systemestimated to affect around $2-3 \%$ of the world population [1-3]. This disease has different types: psoriasis vulgaris, guttate psoriasis, erythrodermic psoriasis, pustular psoriasis and nail psoriasis. The first type is the most common form of psoriasis, which is characterised by red, scaly and raised plaques. Classic psoriasis vulgaris mainly infects specific areas such as elbows, knees and the scalp. It can also remain localized or become generalized over time and the plaques may differ in size $[1,4]$. Treatment of psoriasis depends on many factors such as the extent of the disease, its influence on patient's life, and the life perception of patient's illness [4].

Different types of treatment can be used such as ultra violet B (UVB), psoralen plus ultraviolet A (PUVA), methotrexate (MTX), cyclosporine, vitamin D3 analogues, topical retinoids and topical corticosteroids such as betamethasone dipropionate (BD). BD is a highly potent glucocorticoid receptor agonist which possesses immunosuppressive, anti-inflammatory and anti-proliferative effects. BD has been used in topical therapy for the treatment of mild to moderate psoriasis $[1,2,5-8]$. Targeting of topically applied drugs is becoming a major centre of interest for many pharmaceutical groups working in dermatology to improve drug penetration into different skin layers. Thus; several vesicular systems were used in the treatment of psoriasis such as methotrexate (MTX) loaded liposomes hydrogel $®$, MTX loaded transfersomes $\AA$, MTX loaded niosomes ${ }^{\circledR}$ and corticosteroid nano capsule suspension [9-13]. Transfersomes have been utilized for dermal and transdermal drug delivery, also have several advantages over other nanosystems such as; biocompatibility, biodegradability and transportation of therapeutic agents through narrow constriction without any significant loss [14]. The high deformability of transfersomes gives better penetration of intact vesicles [14].
Therefore; the aim of this work is to design and evaluate betamethasone dipropionate (BD) loaded transfersomes as a topical formulation for the treatment of localized plaque psoriasis.

\section{MATERIALS AND METHODS}

\section{Materials}

Betamethasone dipropionate (BD) was a kind of a gift from $\mathrm{N}$ and $\mathrm{R}$ Bio industries INC, China. Soya Phosphatidylcholine (SPC) and sodium deoxycholate (SDC,>98\%) were purchased from Flukabiochemika company, Saint Gallen, Switzerland. Absolute ethyl alcohol and chloroform were purchased from Fischer scientific company, London, UK. HEPES buffer (4-(2-hydroxyl)-1piperazineethanesulfonic acid): 1 Molar was purchased from Sigma Aldrish Company, St Louis, MO. Tween 80, methyl paraben and propyl paraben were purchased from Acros Organics company, Geel, Belgium. Carboxy methyl cellulose sodium salt (CMC) was purchased from El-Nasr pharmaceutical chemicals co., Adwic, Egypt. Diprosone ${ }^{\circledR}$ cream was produced from Memphis co. for Pharm and Chem. Ind. Cairo-A. R. E under the authority of Schering-Plogh, USA.

Design and preparation of BD loaded transfersomal (BD-T) formulations

\section{Full factorial design}

A $2^{3}$ full factorial design was applied in this study to optimize entrapment efficiency, particle size, zeta potential, polydispersity index and in vitro drug release for the prepared BD-T formulations (table 1). Three factors were selected as independent variables: the drug content (A) at two levels $(25 \mathrm{mg}$ and $50 \mathrm{mg})$, the type of surfactant (B) at two levels (sodium deoxycholate and tween 80) and the amount of surfactants (C) at two levels (5 mg and $7.5 \mathrm{mg}$ ). The experimental trials were performed at all 8 possible combinations. Minitab ${ }^{\circledR}$ release 17 software was used for the generation and evaluation of the statistical experimental design. 
Table 1: Coded units of $2^{3}$ full factorial design for betamethasone dipropionate loaded transfersomal (BD-T) formulations

\begin{tabular}{lll}
\hline Variables & Levels & High \\
\cline { 2 - 3 } & Low & $50 \mathrm{mg}$ BD \\
A (Drug content) & $25 \mathrm{mg} \mathrm{BD}$ & Tween 80 \\
B (Type of surfactant) & Sodium deoxycholate & $7.5 \mathrm{mg}$ \\
C (Amount of surfactant) & $5 \mathrm{mg}$ & -1 \\
Coded values & +1 & \\
\hline
\end{tabular}

Preparation of betamethasone dipropionate loaded transfersomal formulations (BD-T)

Different formulations of BD loaded transfersomes containing $50 \mathrm{mg}$ SPC were prepared by conventional thin lipid film hydration technique using rotary evaporator (Helidolph., Germany) according to formulation composition reported in table (2). The amounts of lipid, surfactant (sodium deoxycholate or tween 80) and drug (BD) were dissolved in $6 \mathrm{ml}$ chloroform and placed in a rotary evaporator for $2 \mathrm{~h}$ at a temperature of $40-42{ }^{\circ} \mathrm{C}$, at a rotation speed of $80-83$ rpm under vacuum. The organic solvent was totally evaporated and the formed lipid film was subsequently hydrated by adding $15 \mathrm{ml}$ of the freshly prepared 0.01 M HEPES buffered saline (PH 5.5) and rotated at a speed of $120-122 \mathrm{rpm}$ for $30 \mathrm{~min}$ at $40-42^{\circ} \mathrm{C}[15,16]$.

\section{Characterization of BD loaded transfersomal (BD-T) formulations}

\section{Determination of entrapment efficiency percentage}

The prepared BD-T formulations (F1-F8) were centrifuged using cooling centrifuge (Helidolph, Germany) at a speed of 40,000 rpm and a temperature of $4{ }^{\circ} \mathrm{C}$ for one hour. The transfersomal residue was separated from the supernatant containing the free drug (FD). The residue was washed twice with $15 \mathrm{ml} 0.01 \mathrm{M}$ HEPES buffered saline and centrifuged for another one hour. The supernatant and the washing solutions were mixed and aliquots $(100 \mu)$ from the mixture were suitably diluted with a mixture of 3:1 ethanol and 0.01 M HEPES buffer saline of $\mathrm{PH}=5.5(\mathrm{Eth}-\mathrm{HS})$ and the free drug concentration was measured spectrophotometrically (Shimadzu, UV-1650 PC, Japan) at $\lambda_{\max }$ of 238 using Eth-HS solution as a blank. [17] Experiment was done in triplicates ( $n=3)$. The BD concentration was calculated using a previously constructed calibration curve of $\mathrm{BD}$ in Eth-HS solution. The calibration curve was linear in the tested concentration range of 5 to $30 \mu \mathrm{g} / \mathrm{ml}\left(\mathrm{R}^{2}=0.9975\right)$. The $\mathrm{EE} \%$ was calculated according to Equation (1).

$\% \mathrm{EE}=$

$\frac{(\text { Total amount of } B D-\text { amount of free drug }[F D])}{\text { Total amount of } B D} \times 100$

Where:

$\% \mathrm{EE}$ is the entrapment efficiency percentage.

$\mathrm{BD}$ is betamethasone dipropionate.

The separated transfersomal residue was resuspended in $15 \mathrm{ml} 0.01$ $\mathrm{M}$ HEPES buffered saline and kept in $4{ }^{\circ} \mathrm{C}$ for further characterization studies (PS, PI, ZP, TEM, and in vitro drug release).

Determination of particle size (PS), polydispersity index (PI) and zeta potential (ZP)

Vesicle properties such as vesicle size, polydispersity index (PI) and zeta potential (ZP) were determined by dynamic light scattering method (DLS), using a computerised inspection system (Zetasizer Nano ZS, Malvern Instruments, Malvern, (UK) at room temperature. The samples of BD-T were diluted 10 times using distilled water for measuring particle size [11]. For measuring zeta potential, samples were transferred to disposable plain folded capillary zeta cells without dilution and all measurements were done in triplicates [18].

\section{Transmission electron microscope (TEM)}

The BD-T formulations were visualized by transmission electron microscope (TEM, JOEL, Japan). For each formulation, one drop from diluted samples (10 times) with distilled water was loaded on a carbon grid; left for 2 min for dryness and pigmented with uranyl acetate $70 \%$ saturated solution of alcohol. The excess of staining solution was drained off with a filter paper $[17,19]$.

\section{In vitro drug release study}

A volume of $0.5 \mathrm{ml}$ of each transfersomal formulations was placed in a dialysis bag of $2 \mathrm{~cm}$ length (Dialysis tubing-visking: regenerated cellulose, size 5 inf Dia 24/32"-19 mm: 30 M, Medicell. UK). Both ends were tied and the dialysis bag was suspended in $15 \mathrm{ml}$ Eth-HS solution of $\mathrm{PH}=5.5$ and maintained at $37 \pm 0.5^{\circ} \mathrm{C}$. The system was stirred magnetically at $200 \mathrm{rpm}$. At predetermined time intervals; 2 $\mathrm{ml}$ aliquots of the release medium was sampled and replaced with 2 $\mathrm{ml}$ fresh Eth-HS solution. The samples were suitably diluted with Eth-HS solution and the drug concentration was measured spectrophotometry at $\lambda_{\max }$ of $238 \mathrm{~nm}$ [20]. Drug concentration was determined using the previously prepared standard curve of BD in Eth-HS solution and all experiments were conducted in triplicates.

\section{Preparation of BD-T gel}

The selected optimized BD-T formulation was prepared as a hydrogel using $5 \%$ sodium carboxymethyl cellulose (Na-CMC) as a gelling agent. Na-CMC gel was prepared by adding the gelling agent on the transfersomal suspension in warm water with continuous stirring until complete dispersion. The final concentration of BD in the BD-T gel was $0.05 \%$ to be comparable to the BD concentration in the marketed product (Diprosone ${ }^{\circledR}$ cream). Finally, the preservatives; methyl paraben $(0.1 \%)$ and propyl paraben $(0.2 \%)$ was added with continuous stirring. The gel was left for $24 \mathrm{~h}$ for complete swelling and removal of air bubbles.

\section{Characterization of BD-T gel}

\section{Organoleptic properties}

The organoleptic properties of the prepared BD-T gel were tested such as color, odor, texture and transparency.

\section{Rheological study}

A sample of one gram was tested in order to identify the flow behaviour of the gel (Cone over the plate, V type, Brookfield viscometer, UK). The shear stress in dyne $/ \mathrm{cm}^{2}$ and the viscosity in centipose were determined at a different shear rate $(2,6,10,20,24$, 60, 100 and $120 \mathrm{sec}^{-1}$ ) using spindle number 52.

\section{In vitro $\mathrm{BD}$ release}

The in vitro drug release from BD-T gel was studied using a USP dissolution apparatus (Electro lab model TDT-08L, India) with 8 cells each containing $250 \mathrm{ml}$ vessel. One gram of BD-T gel was placed in a glass watch of $5 \mathrm{~cm}$ diameter and covered with a dialysis membrane (size 5 inf Dia 24/32"-19 mm: 30 M, Medicell. UK). Each glass watch was placed in dissolution vessels containing $100 \mathrm{ml}$ of the dissolution medium (Eth-HS solution) at $32 \pm 0.5{ }^{\circ} \mathrm{C}$ (skin temperature). The dissolution medium was stirred with a paddle at a constant rate of 100 rpm $[11,21]$. Samples of $2 \mathrm{ml}$ were withdrawn from the dissolution medium at specified time intervals and were suitably diluted with EthHS solution before measuring the concentration of BD released. The drug concentration was measured spectrophotometrically at $\lambda_{\max }$ of $238 \mathrm{~nm}$ using the previously constructed calibration curve.

\section{Stability study}

The stability of BD loaded transfersomes was evaluated after storage for 6 mo at $4{ }^{\circ} \mathrm{C}$ and $25^{\circ} \mathrm{C}$ by studying the change in the organoleptic characters, drug content (chemical stability) and in vitro drug release (physical stability) [19, 22-29]. 
The drug content was determined by dissolving a weight of $0.5 \mathrm{gm}$ of the freshly prepared BD-T gel in $50 \mathrm{ml}$ Eth-HS solution. Two ml. samples were filtered and analyzed spectrophotometrically at $\lambda_{\max }$ of $238 \mathrm{~nm}$ after suitable dilution with Eth-HS solution.

\section{Clinical study}

Twenty patients with plaque psoriasis, with an age range of 24 to $60 \mathrm{y}$ were enrolled in this study. The experimental protocol was approved by an ethical committee at Faculty of Pharmacy, Tanta University. The patients were enrolled from the outpatient dermatology clinics, Tanta University hospital. Patients were subdivided into two equal groups. Group 1: for treatment with BD-T gel and Group 2: for treatment with marketed product. For each patient; one side was treated with the tested product and the other side was treated with placebo gel. The exclusion criteria were pregnancy, lactation and prohibition from topical corticosteroids. Patients were given treatment three times daily. Physician global assessment (PGA) score of improvement was calculated at base line and after 2 mo of treatment. The PGA scores were 0 (clear), 1(minimal), 2(mild), 3 (moderate), 4 (severe) and 5 (very severe) [30-35].

\section{Kinetic analysis}

The release data were analyzed mathematically according to zero order, first order and Higuchi models [equations 2 to 4 ] using StatisiXL for MS Excel software. The release rate constants $(\mathrm{K})$ and half-lives $\left(\mathrm{T}_{\mathbf{5 0}}\right)$ were estimated.

$$
\text { Zero order: } \mathrm{C}=\mathrm{K}_{0} \mathrm{t} \text {................. Equation (2) }
$$

First order: $\log C t=\log C_{0}-K 1 t / 2.303 \ldots \ldots . .$. Equation (3)

Higuchi Model: $\log \mathrm{Q} t=\log \mathrm{KH}+1 / 2 \log \mathrm{t} \ldots \ldots \ldots . .$. Equation (4) Where:

$\mathrm{K}_{0}$ is the zero-order rate constant (concentration/time).

$\mathrm{t}$ is the time $(\mathrm{h})$.

Ct is the amount of drug released in time $t$.

$\mathrm{C}_{0}$ is the initial concentration of the drug.
$\mathrm{K}$ is the first order constant.

Qt is the amount of drug release in time $t$.

$\mathrm{KH}$ is the Higuchi dissolution constant.

\section{Statistical analysis}

Statistical analysis of the results from the determined parameters in the present study was carried out using MINITAB statistical software (Minitab release 17) and SPSS statistical software (SPSS release 20). A polynomial equation was used to fit the data by multiple regressions procedure. Regression analysis was performed to find the interactive impact of the three independent variables on entrapment efficiency (EE), particle size (PS), zeta potential (ZP), polydispersity index (PI) and in vitro drug release. This resulted in an empirical model that relates the response measured to the independent variables of the experiment. For a 3-factor system; the model equation is:

$\mathrm{Y}=\mathrm{b}_{0}+\mathrm{b}_{1} \mathrm{~A}+\mathrm{b}_{2} \mathrm{~B}+\mathrm{b}_{3} \mathrm{C}+\mathrm{b}_{4} \mathrm{AB}+\mathrm{b}_{5} \mathrm{AC}+\mathrm{b}_{6} \mathrm{BC}+\mathrm{b}_{7} \mathrm{ABC} \ldots \ldots \ldots$. Equation

Where:

$\mathrm{Y}$ the predicted response.

$b_{o}$ the intercept.

$b_{1}, b_{2}$, and $b_{3}$ the linear coefficients.

$\mathrm{b}_{4}, \mathrm{~b}_{5}, \mathrm{~b}_{6}$ and $\mathrm{b}_{7}$ the interaction coefficients.

\section{$\mathrm{A}, \mathrm{B}, \mathrm{C}, \mathrm{AB}, \mathrm{AC}, \mathrm{BC}$ and $\mathrm{ABC}$ independent variables.}

The mean effect $(\mathrm{A}, \mathrm{B}, \mathrm{C})$ represents the average result of changing one factor at a time from its low to high level. The interaction terms $(\mathrm{AB}, \mathrm{AC}, \mathrm{BC}$ and $\mathrm{ABC})$ show how the response changes when two factors are changed simultaneously.

\section{RESULTS}

\section{In vitro characterization of BD-T formulations}

Composition and characteristics of prepared BD-T formulations are represented in the table (2).

Table 2: In vitro characteristics of betamethasone dipropionate loaded transfersomal (BD-T) formulations

\begin{tabular}{|c|c|c|c|c|c|c|c|}
\hline \multirow[t]{2}{*}{ Batch code } & \multicolumn{3}{|c|}{ Formulation composition } & \multicolumn{4}{|c|}{ In vitro characteristics } \\
\hline & $\begin{array}{l}\text { Drug content } \\
\text { (mg) }\end{array}$ & Surfactant type & $\begin{array}{l}\text { Surfactant } \\
\text { content (mg) }\end{array}$ & EE \% $\%$ S. D & PS \pm SD & $\mathrm{PI} \pm \mathrm{SD}$ & $\mathrm{ZP} \pm \mathrm{SD}$ \\
\hline F1 & 25 & SDC & 5 & $82.1 \pm 0.76$ & $529.80 \pm 0.20$ & $0.727 \pm 0.002$ & $-18.60 \pm 0.10$ \\
\hline $\mathrm{F} 2$ & 50 & SDC & 5 & $82.6 \pm 0.55$ & $358.80 \pm 1.20$ & $0.6 \pm 0.020$ & $-7.25 \pm 1.00$ \\
\hline F3 & 25 & Tween 80 & 5 & $88.6 \pm 0.51$ & $390.10 \pm 0.90$ & $0.448 \pm 0.020$ & $-12.70 \pm 1.00$ \\
\hline F4 & 50 & Tween 80 & 5 & $90.2 \pm 0.48$ & $242.80 \pm 1.20$ & $0.407 \pm 0.020$ & $-15.00 \pm 1.00$ \\
\hline F5 & 25 & SDC & 7.5 & $69.2 \pm 0.74$ & $674.00 \pm 1.00$ & $0.562 \pm 0.020$ & $-14.30 \pm 1.00$ \\
\hline F6 & 50 & SDC & 7.5 & $55.5 \pm 0.42$ & $279.60 \pm 0.40$ & $0.524 \pm 0.001$ & $-20.50 \pm 0.50$ \\
\hline F7 & 25 & Tween 80 & 7.5 & $78.2 \pm 0.54$ & $250.50 \pm 1.50$ & $0.416 \pm 0.001$ & $-13.10 \pm 1.00$ \\
\hline F8 & 50 & Tween 80 & 7.5 & $72.2 \pm 0.80$ & $396.30 \pm 1.30$ & $0.396 \pm 0.002$ & $-16.70 \pm 0.40$ \\
\hline
\end{tabular}

Eachf ${ }^{\circ} \mathrm{rmulati}{ }^{\circ} \mathrm{nc}{ }^{\circ} \mathrm{ntains}[50] \mathrm{mgSPC}\left(\mathrm{s}^{\circ} \mathrm{yaph}{ }^{\circ}\right.$ sphatidylch ${ }^{\circ}$ line),SDCiss ${ }^{\circ}$ diumde ${ }^{\circ} \mathrm{xych}{ }^{\circ}$ late, EEis the entrapment efficiency (\%), PSis the particle size $(\mathrm{nm})$, PIisthep ${ }^{\circ}$ lydispersityindexand Z Pisthezetap ${ }^{\circ}$ tential $(\mathrm{mV})$, dataaremean $\pm \mathrm{SD}, \mathrm{n}=3$.

\section{Entrapment efficiency percentage}

The entrapment efficiency of different transfersomal formulations are reported in the table (2). From the table, the transfersomes prepared from low content of surfactant showed the highest EE irrespective to the type of surfactant. The regression equation representing the effect of independent variables on the $\mathrm{EE} \%$ was equation (6). The equation showed that the most effective factor on EE \% was the surfactant content (c) in its low level. The second effective factor was B in its high level (tween 80). The third one was the interaction $\mathrm{AC}$ in its low level indicating that high $\mathrm{EE} \%$ was achieved by the use of $+\mathrm{A}$ (high drug content) and-C (low surfactant content). All the factors showed a significant effect on EE \%

$\mathrm{EE} \%=77.4-2.28 \mathrm{~A}+4.87 \mathrm{~B}-8.45 \mathrm{C}+1.19 \mathrm{AB}-2.82 \mathrm{AC}+1.37 \mathrm{BC}+0.914$ $\mathrm{ABC}$ Equation (6)
Where:

$\mathrm{EE} \%$ is the entrapment efficiency percentage.

Particle size (PS), polydispersity index (PI) and zeta potential (ZP) measurements

The regression equation (7) representing the effect of independent variables on the particle size showed that the most effective factor was the drug content (A) in its high level. The second effective factor was B (the type of surfactant) in its high level and the third effective factor was the interaction $\mathrm{ABC}$ in its negative level. All the factors showed a significant effect on PS.

$\mathrm{PS}=390-70.9 \mathrm{~A}-70.3 \mathrm{~B}+9.86 \mathrm{C}+70.5 \mathrm{AB}+8.71 \mathrm{AC}-6.39 \mathrm{BC}+64.6 \mathrm{ABC}$ Equation (7) 
Where:

PS is the particle size.

The regression equation (8) representing the effect of independent variables on the PI showed that the most effective factor was B in its high level (tween 80), the second effective factor was C (surfactant content) in its high level and the third effective factor was A in its high level (high drug content). All the factors showed significant effects $(\mathrm{p}<0.05)$ on PI except the interaction ABC.

PI $=0.510-0.0288 \quad \mathrm{~A}-0.0935 \quad \mathrm{~B}-0.0358 \quad \mathrm{C}+0.0125 \quad \mathrm{AB}+0.0133$ $\mathrm{AC}+0.0245 \mathrm{BC}-0.00900 \mathrm{ABC}$ Equation (8).

Where:

PI is the poly dispersity index.

The regression equation (9) representing the effect of independent variables on the $\mathrm{ZP}$ showed that the most effective factor was the interaction $\mathrm{AC}$ in its high level; $+\mathrm{A}$ (high drug content) and $+\mathrm{C}$ (high surfactant content). The second effective factor was the interaction $A B C$ in its low level and the third one was $+C$ (high surfactant content). All the factors showed significant effects $(p<0.05)$ on ZP except the factor A (drug content).

$\mathrm{ZP}=14.8+0.094 \mathrm{~A}-0.394 \mathrm{~B}+1.38 \mathrm{C}+1.38 \mathrm{AB}+2.36 \mathrm{AC}-0.856 \mathrm{BC}-2.03$ $\mathrm{ABC}$ Equation (9)

Where:

$\mathrm{ZP}$ is the zeta-potential.

\section{Transmission electron microscopy (TEM)}

The TEM photographs for the eight tested formulations showed great variations in shape with nano size of the transfersomal vesicles. Formulations F1 to F4 showed typical spherical shape, unilamellar structure and smooth surface vesicles and formulations F5 to F8 showed high deformation in the shape of the formed vesicles. Photographs of F4 and F8 represent the formulations F4 (a) and F8 (b) as shown in fig. 1.

\section{In vitro drug release}

The drug release profiles from the eight BD-T formulations are represented in fig. 2. The Percentages of BD released from BD-T formulations after $0.75 \mathrm{~h}$ were ranged from $2.37 \pm 0.03 \%$ to $9.50 \pm 0.50 \%$.

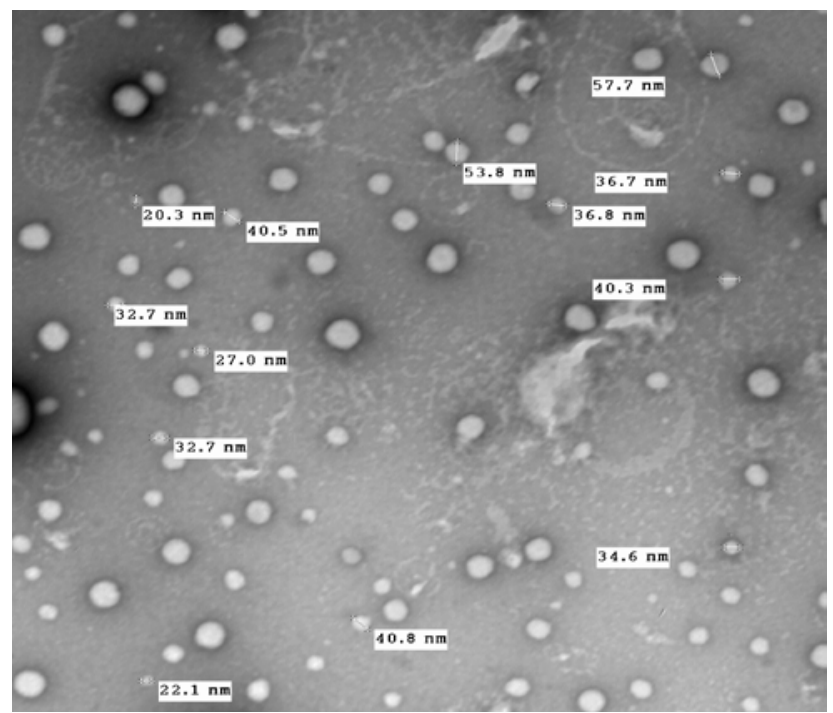

(a)
The results of the kinetic analysis of the release data are reported in the table (3). All formulations showed best fitting to zero order kinetics $\left(\mathrm{K}_{0}\right)$. From the table, $\mathrm{F} 4$ was the formulation that showed the highest release rate. The regression equation representing the effect of independent variables on the release rate constant $\left(\mathrm{K}_{0}\right)$ was equation (10). From the equation, the most effective factor on increasing $\mathrm{K}$ was An in its high level (high drug content). The second effective factor was the interaction $\mathrm{BC}$ in its low level resulted from the interaction of the factor-C with the factor+B. The third one was $B$ in its high level (tween 80). All the factors showed significant effects $(p<0.05)$ on $K_{0}$ except the interaction $A B$ and the interaction $\mathrm{ABC}$.

$\mathrm{K}_{0}=2.61+1.18 \mathrm{~A}+0.170 \mathrm{~B}-0.0936 \mathrm{C}-0.00669 \mathrm{AB}+0.0507 \mathrm{AC}-0.293 \mathrm{BC}-$ $0.0073 \mathrm{ABC}$ Equation (10)

Where:

$\mathrm{K}_{0}$ is zero order release constant.

A graphical representation of contour plots for the effects of the most effective factors on EE, particle size and release rate constant is showed in fig. 3 ( $a, b$ and $c)$.

\section{In vitro characterization of BD-T gel}

The prepared BD-T gel was elegant, soft, odorless, colourless and having a transparent appearance. The gel exhibited a pseudoplastic flow with a thixotropic behaviour which was a desirable character in pharmaceutical gels. The rheological parameters for the prepared BD-T gel were calculated according to equations (11) and (12) of the power law and listed in the table (4) [36, 37]. The drug release profile was best fitted to Higuchi diffusion model with release rate constant $\mathrm{K}_{\text {dif }}=11.0 \pm 0.01 \mathrm{mg} / \mathrm{hr}^{-1}$ and $\mathrm{T}_{50}$ of $5.15 \pm 0.1 \mathrm{~h}$.

$$
\eta=K \cdot \gamma^{(n-1)} \text { Equation (11) }
$$

Where:

$\eta$ is the viscosity in cp.

$\mathrm{K}$ is the consistency index.

$\gamma$ is the shear rate in sec-1.

$\mathrm{n}$ is the flow behaviour index.

$$
\log \eta=\log K+\log \gamma \cdot(n-1) \ldots \ldots . . . \text { Equation (12) }
$$

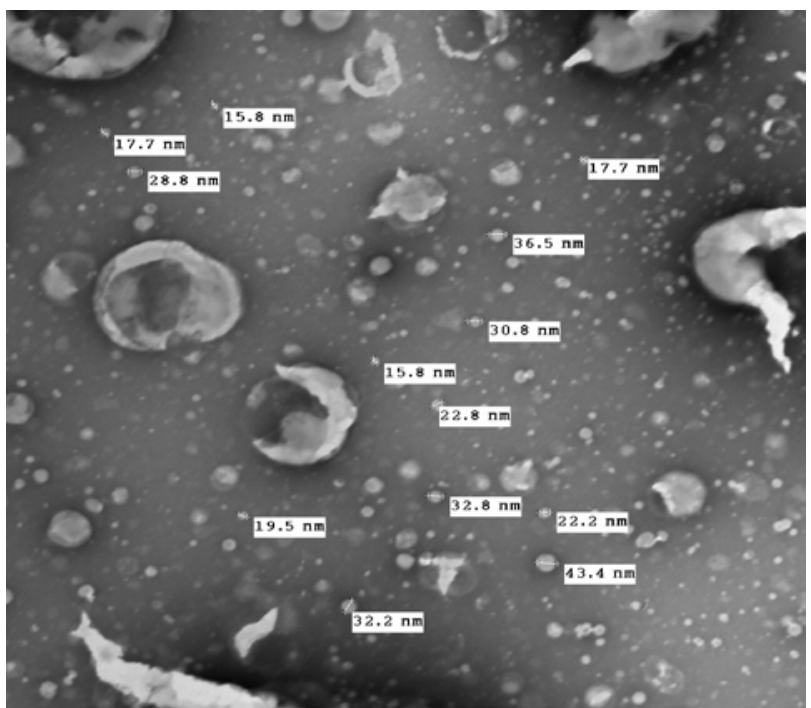

(b)

Fig. 1: Transmission electron microscope (TEM) photographs of betamethasone dipropionate loaded transfersomal formulations F4 (a) and F8 (b), (magnification x 7500) 


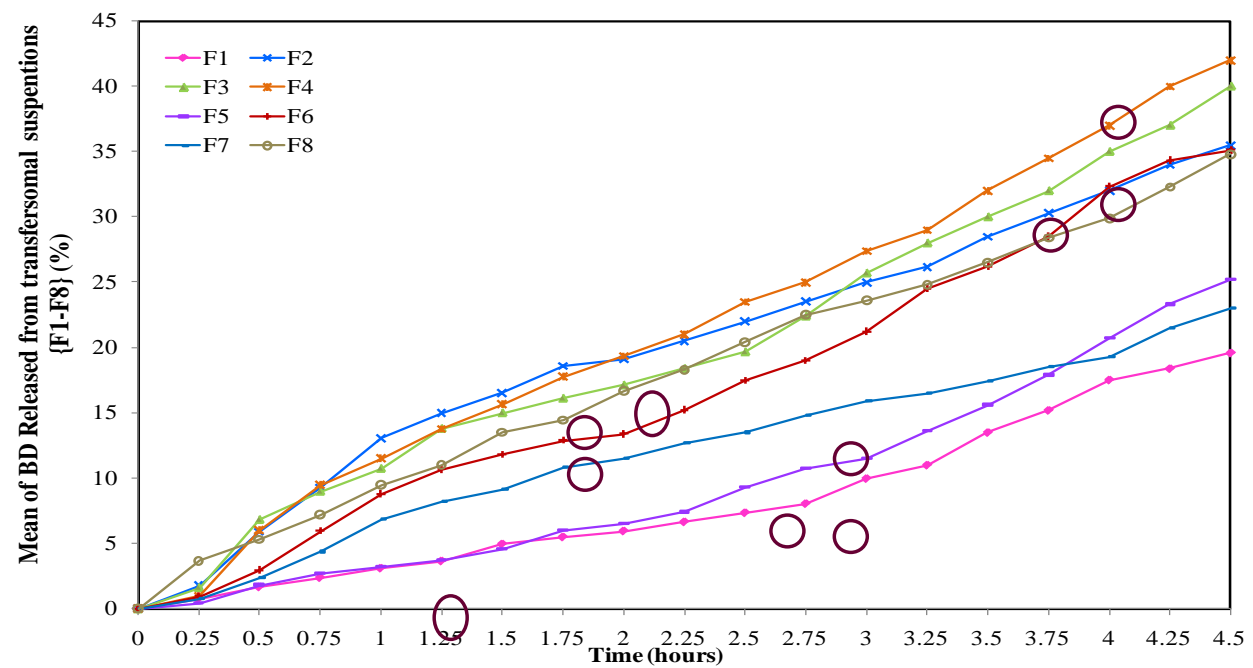

Fig. 2: In vitro drug release profile from betamethasone dipropionate loaded transfersomal formulations, Data $\operatorname{are}$ mean $\pm S D, n=3$ for each formulation

Table 3: Drug release kinetic parameters for BD-T formulations

\begin{tabular}{lll}
\hline Formulation No. & $\mathbf{K}_{\mathbf{0}}$ & $\left.\mathbf{T}_{\mathbf{5 0}} \mathbf{( h r}\right)$ \\
\hline F1 & $1.097 \pm 0.015$ & $11.34 \pm 0.056$ \\
F2 & $3.375 \pm 0.025$ & $7.407 \pm 0.055$ \\
F3 & $2.035 \pm 0.029$ & $6.093 \pm 0.006$ \\
F4 & $4.290 \pm 0.026$ & $5.827 \pm 0.038$ \\
F5 & $1.393 \pm 0.011$ & $8.973 \pm 0.068$ \\
F6 & $3.877 \pm 0.012$ & $6.45 \pm 0.017$ \\
F7 & $1.162 \pm 0.029$ & $10.607 \pm 0.060$ \\
F8 & $3.623 \pm 0.038$ & $6.9 \pm 0.0700$ \\
\hline
\end{tabular}

Data are mean $\pm S D, n=3 K_{0}$ : release rate constant presented as $m g . h^{-1}$

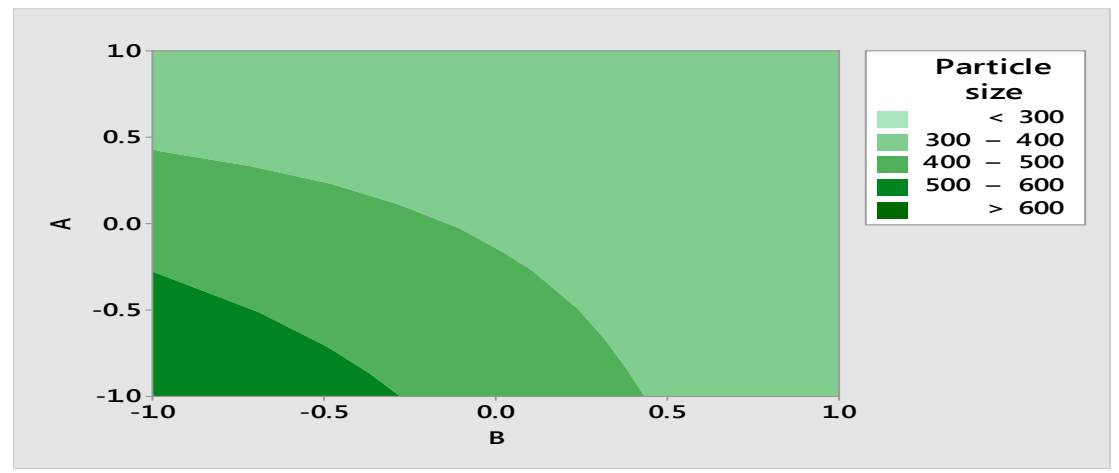

(b)

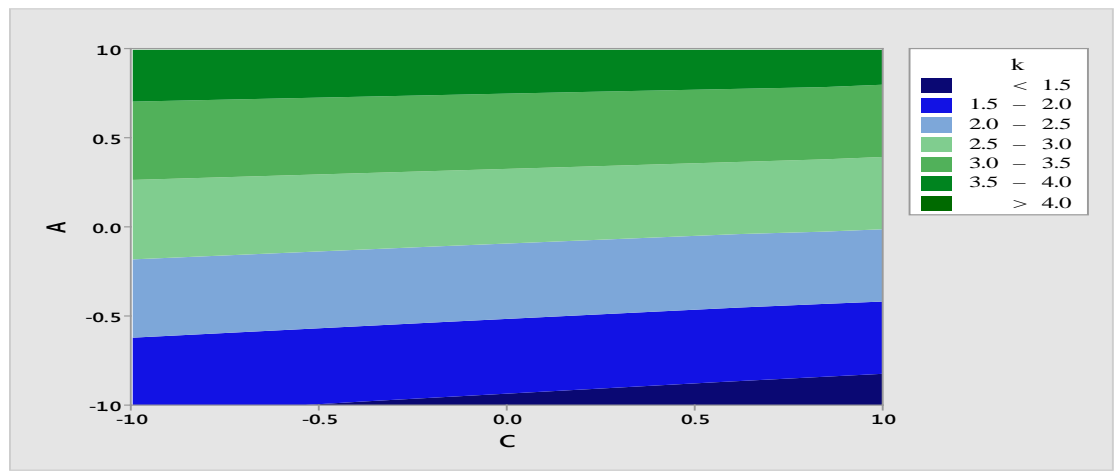

(c)

Fig. 3: Contour plots for the effects of the most effective factors on entrapment efficiency\% (a), particle size (b) and release rate constant (c), n=3 for all formulations 
Table 4: Rheological parameters of the prepared pseudoplastic BD-T gel

\begin{tabular}{llll}
\hline System & $\mathbf{R}^{2}$ & $\mathbf{n}$ & $\mathbf{K}$ \\
\hline BD-T gel & $0.9447 \pm 0.0053$ & $0.6553 \pm 0.0004$ & $6696.28 \pm 11.581$ \\
\hline
\end{tabular}

BD-T gel betamethasone dipropionate loaded transfersomal gel, $\mathrm{R}^{2}$ is the regression coefficient, $\mathrm{n}$ is the flow index, $\mathrm{K}$ is the consistency index, sample size $=3$, data are mean \pm SD

\section{Stability of BD-T gel}

All organoleptic characters including shape, consistency, color and odor; didn't changed over six month's storage at $4{ }^{\circ} \mathrm{C}$ and $25^{\circ} \mathrm{C}$. Drug release from the gel during 6 mo was used as an indication for physical stability. There was the insignificant difference between drug released from gel during $6 \mathrm{mo}(\mathrm{p}=0.144)$ either at $4{ }^{\circ} \mathrm{C}$ or at 25 ${ }^{\circ} \mathrm{C}$ (table 5). The release kinetics was best fitted to Higuchi diffusion model. From the table, there were no significant changes in the drug content during six months storage at $4{ }^{\circ} \mathrm{C}$ and $25{ }^{\circ} \mathrm{C}$ indicating the drug chemical stability.

\section{Clinical evaluation of BD-T gel}

The relation between clinical efficacy and patient's age, sex and duration of illness in both groups were statistically evaluated, and the results showed insignificant effect $(\mathrm{p}>0.05)$ of patient's age on the clinical efficacy of both BD-T gel and marketed cream. An overall comparison between the clinical efficacies of both groups was showed in the table (6),which showed that there was a statistically significant difference in the clinical efficacy between groups treated with BD-T gel and Diprosone ${ }^{\circledR}$ cream $(p=0.016)$. The comparison between the two groups regarding safety and tolerability was represented in fig. 4. The results indicated that BD-T was more safe and tolerable compared with the reference product $(p=0.00)$. From table (5), $30 \%$ of the patients treated with BD-T gel showed clear score (0), $60 \%$ showed minimal score (1) and $10 \%$ showed mild score (2). The patients treated with BD cream showed that $10 \%$ was a clear score (0), 10\% was minimal (1) and $50 \%$ was mild (2), and $30 \%$ showed moderate score (3). The patient's response to the treatment in both groups wasn't affected significantly with the difference in age $(p=0.093), p>0.05$, gender $=1$ and duration of illness $\mathrm{p}=0.233$. There was statistically difference between score before treatment and score after treatment. The clinical results for Group (1) and Group (2) are showed in fig. 5.

Table 5: Drug release kinetic parameters and drug content for betamethasone dipropionate loaded transfersomal gel during storage for six months

\begin{tabular}{lllll}
\hline $\begin{array}{l}\text { Storage } \\
\text { conditions }\end{array}$ & Storage times (months) & Drug content & $\mathbf{K}_{\text {dif }}\left(\mathbf{m g} / \mathbf{h r} \mathbf{1}^{\mathbf{1} / \mathbf{2}}\right)$ & $\mathbf{T}_{\mathbf{5 0}}$ (hr) \\
\hline & & & $11.02 \pm 0.100$ & $5.145 \pm 0.096$ \\
$4{ }^{\circ} \mathrm{C}$ & fresh & $97.60 \pm 1.01$ & $11.02 \pm 0.017$ & $5.151 \pm 0.016$ \\
& 1 & $98.50 \pm 0.50$ & $10.92 \pm 0.079$ & $5.243 \pm 0.076$ \\
& 2 & $97.83 \pm 0.49$ & $11.02 \pm 0.010$ & $5.151 \pm 0.009$ \\
& 3 & $97.73 \pm 0.68$ & $11.02 \pm 0.030$ & $5.146 \pm 0.028$ \\
& 4 & $97.73 \pm 0.31$ & $10.96 \pm 0.031$ & $5.205 \pm 0.030$ \\
$2{ }^{\circ} \mathrm{C}$ & 5 & $96.63 \pm 0.85$ & $10.98 \pm 0.015$ & $5.186 \pm 0.014$ \\
\hline
\end{tabular}

Data are mean $\pm S D, n=3$

Table 6: Comparison between the two studied groups according to Physician global assessment (PGA) score

\begin{tabular}{|c|c|c|c|c|}
\hline & Group I & Group II & $\chi^{2}$ & MCp \\
\hline & $\%$ & $\%$ & & \\
\hline Score before & & & & \\
\hline Clear & 0.0 & 0.0 & 1.116 & 0.835 \\
\hline Minimal & 0.0 & 0.0 & & \\
\hline Mild & 0.0 & 0.0 & & \\
\hline Moderate & 50.0 & 50.0 & & \\
\hline Severe & 30.0 & 30.0 & & \\
\hline Very Severe & 20.0 & 20.0 & & \\
\hline Score for Cor & & & & \\
\hline Clear & 0.0 & 0.0 & 1.050 & 0.712 \\
\hline Minimal & 0.0 & 0.0 & & \\
\hline Mild & 0.0 & 0.0 & & \\
\hline Moderate & 50.0 & 40.0 & & \\
\hline Severe & 30.0 & 50.0 & & \\
\hline Very Severe & 20.0 & 10.0 & & \\
\hline Score after tr & & & & \\
\hline Clear & 30.0 & 10.0 & $9.424^{*}$ & $0.016^{*}$ \\
\hline Minimal & 60.0 & 10.0 & & \\
\hline Mild & 10.0 & 50.0 & & \\
\hline Moderate & 0.0 & 30.0 & & \\
\hline Severe & 0.0 & 0.0 & & \\
\hline Very Severe & 0.0 & 0.0 & & \\
\hline
\end{tabular}

$\chi^{2}$ : Chi square test, MC: Monte Carlo for Chi square test, *: Statistically significant at $\mathrm{p} \leq 0.05$ 


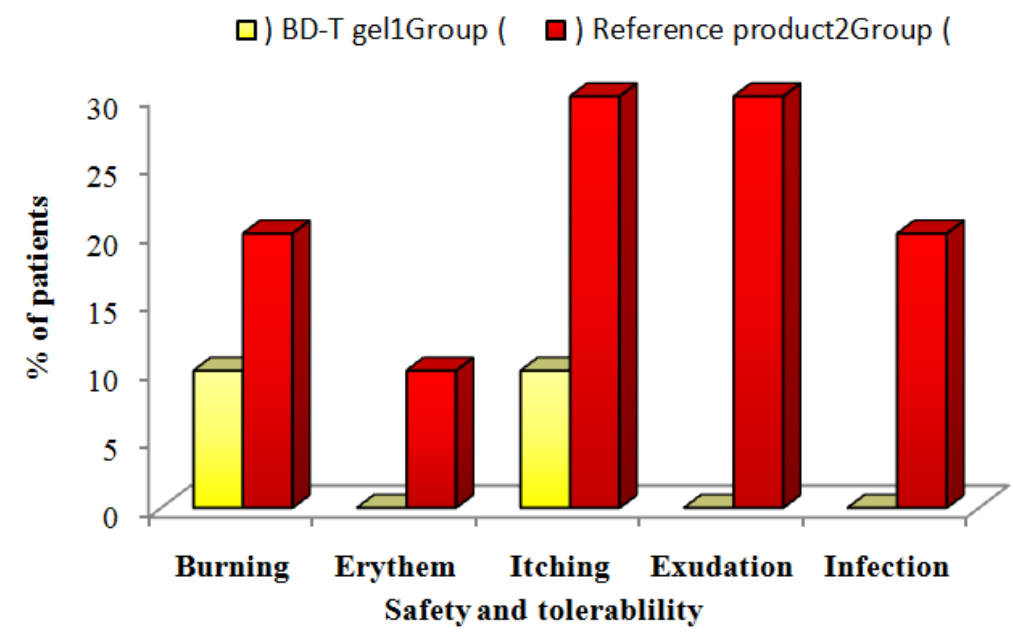

Fig. 4: Comparison between the two groups as regards safety and tolerability

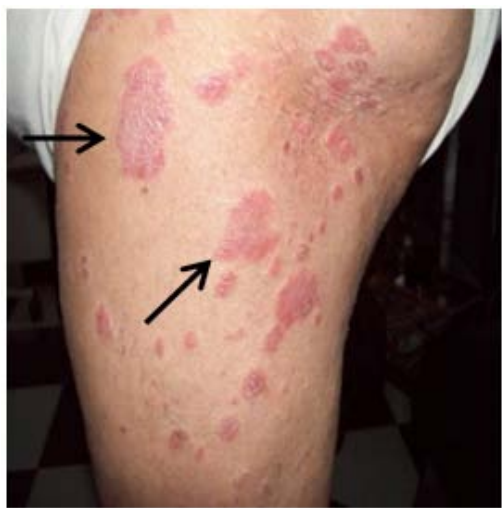

(a)

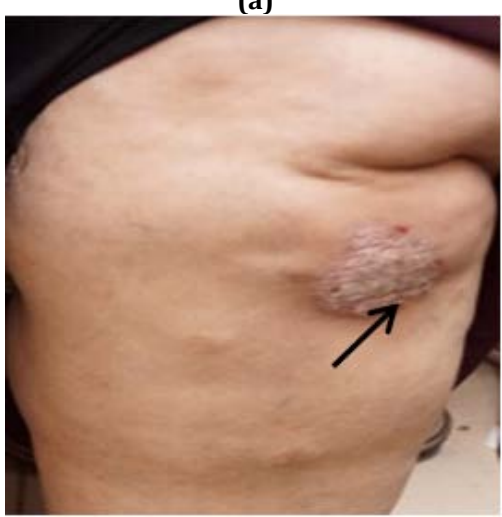

(c)

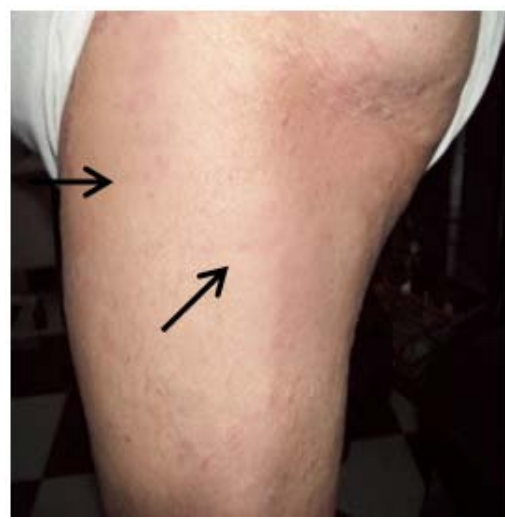

(b)

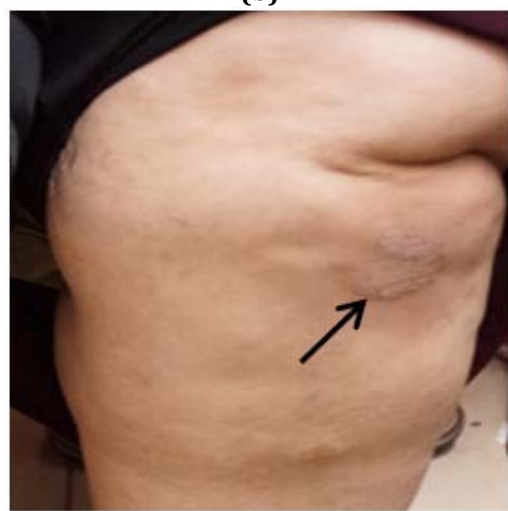

(d)

Fig. 5: A female patient with plaque type psoriasis: (a) left leg before treatment (PGA 4), (b) left leg after treatment with BD-T gel, (PGA 1), A female patient with plaque type psoriasis; (c) left leg before treatment $(P G A=3)$ and (d) left leg after treatment with diprosone cream for 2 mo (PGA=1), PGA is physician global assessment, BD-T gel is betamethasone dipropionatel oaded transfers omalgel

\section{DISCUSSION}

The use of thin film hydration method in the present work may be advantageous in improving EE compared with vortexing method [22] All the tested BD-T formulations showed a relatively high EE\% ranged from $69.1 \% \pm 0.80$ to $90.1 \% \pm 0.76$ (table 2). This increase in EE\% may be attributed to the formation of a thin film with a large surface area which facilitates the complete hydration of vesicles [22].

Concerning EE\%, the regression equation (6) showed that the formulation F4 was the optimized one due to the low surfactant content $(-\mathrm{C})$, tween $80(+\mathrm{B})$ and high drug content $(+\mathrm{A})$. These results agreed with that reported by El-Zaafrany et al. [22]. The authors found that increasing surfactant content from $2 \%$ to $5 \%$ $(\mathrm{W} / \mathrm{W})$ increased the EE\% non-significantly but further increase in its content showed a decrease in EE\%.

The same finding was reported by Jain et al. [19], where they showed that EE\% decreased with an increase in surfactant concentration. The authors explained these results by the possible coexistence of mixed micelles and vesicles at higher surfactant concentration, and consequently lower drug entrapment efficiency. The second effective factor was B (type of surfactant) in its high level; vesicles containing tween 80 have higher EE than vesicles 
containing SDC. To explain these findings we considered HLB (hydrophilic/lipophilic balance) of the two surfactants [22]. The HLB values for tween 80 and SDC are 15 and 16.7, respectively [22]. Based on these HLB values, affinity for lipids was expected to be higher in the case of using tween 80 rather than SDC and incorporation of $\mathrm{BD}$ as a lipophilic drug was easier in the non-ionic surfactant compared with the anionic surfactant. This result reflected the relationship between the hydrophobicity of the drug and that of the surfactant as reported by El-Zafraany [22]. Another explanation for the higher EE showed by tween 80 may be due to its high solubilizing effect. The last effective factor was the interaction$\mathrm{AC}$ where; the use of high drug content $(+\mathrm{A})$ with the low surfactant content $(-\mathrm{C})$ lead to a significant increase in $\mathrm{EE} \%$.

Concerning PS, The regression equation (7) showed that the formulation $\mathrm{F} 4$ was the optimized one due to the use of high drug content $(+A)$, tween $80(+B)$ and low surfactant content $(-C)$. The particle size of the prepared transfersomes decreased significantly $(p \leq 0.05)$ by increasing drug content from $25 \mathrm{mg}$ to $50 \mathrm{mg}$. This may be due to the partitioning of the lipophilic drug into the coating layer resulting in an increase of its rigidity. Consequently, this enhanced the stability of vesicles with the smaller size. Also, from the regression equation (7); the second effective factor was $B$ in its high level (tween 80 ). This result was explained by the solubilizing effect and the HLB value of tween 80 [38-40]. Generally, the use of edge activators with lower HLB resulted in vesicles with the smaller size as in the case of tween 80 compared with SDC [22]. This relationship observed between vesicle size and surfactant HLB was attributed to the decrease in surface energy obtained with increasing hydrophobicity that results in smaller vesicles. The third effective factor was the interaction $A B C$ in its low level where the use of low surfactant content $(-C)$ with high drug content $(+A)$ and tween 80 (+B) significantly reduced particle size.

The polydispersity index (PI) gives an important indication concerning sample homogeneity; as a value below 0.7 reflect relatively homogenous nanoparticles, with a minimum predisposition to aggregation [41]. PI values of all formulations were found to be in a narrow range (0.396-0.727). The regression equation (8), showed that the formulation F8 was the optimised one due to the use of tween $80(+B)$, high surfactant content $(+C)$ and high drug content $(+A)$. The results showed that PI decreased significantly upon using tween $80(\mathrm{p}<0.05)$ compared with those prepared with SDC. Huang et al. [42] were in agreement with the current results indicating that PI could be well controlled by incorporation of tween 80 . This indicated a quite homogenous population of tween 80 containing vesicles. The second effective factor was $\mathrm{C}$ (surfactant content) in its high level. The increase in surfactant content resulted in the formation of more homogenous micelles with low PI values. This may be due to the effect of higher concentration of tween 80 on physical stabilization of transfersomes that prevented or decreased its aggregation. The third effective factor was +A (high drug content); as the drug content increased, the PI decreased. This may be explained by the increased stability of the mixed micelles formed and consequently, the decreased tendency for aggregation.

Zeta potential (ZP) was measured via the electrophoretic mobility of the particles in an electric field [43]. ZP is one of the factors that determine the physical stability of nanosystems [44-46]. The regression equation (9) showed that the formulation F6 was the optimized one due to the use of high drug content $(+A)$, high surfactant content $(+C)$ and SDC $(-B)$. The most effective variable on $\mathrm{ZP}$ was the interaction AC in its high level. This result indicated the synergistic interaction between high drug content $(+A)$ and high surfactant content $(+C)$. This result agreed with that reported by Basha et al. [46], who found that the increase in surfactant concentration (sodium cholate, sodium deoxychloate, tween 80 ) increases the ZP value of the nanovesicles. In addition, GonzalezMira et al. [47], reported that the higher concentration of the loaded drug (flurbiprofen) leads to higher ZP. The second effective factor significantly increased $\mathrm{ZP}$ value was the interaction- $\mathrm{ABC}$ indicating the significant effect of using of $+A,+C$ and $-B$ (SDC). This was in agreement with that reported by Basha et al. [46], who found that nanovesicles prepared with SC and SDC showed more negative ZP values attributed to their anionic nature compared with tween 80 with its non-ionic nature. Despite of the regression equation showed that F6 is the optimized it is not necessarily to be the most physically stable one. This is because ZP indicates only the electrical hindrance. Transfersomes prepared with tween 80 showed electrical and steric hindrance [42]. This steric hindrance prevented the aggregation and stabilized the system physically.

TEM showed that the use of high surfactant contents resulted in high deformation in the shape of the formed vesicles as showed in (fig. 1). This deformation may be explained by the formation of mixed micelles in combination with the transfersomal vesicles [22].

The in vitro release of all formulations were best fitted to zero order kinetics as indicated by the highest correlation coefficients. Concerning in vitro drug release, the regression equation (10) showed that the formulation F4 is the optimized one due to the use of high drug content $(+A)$, low surfactant content $(-C)$ and tween 80 $(+B)$. The most effective factor was the high drug content $(+A)$. This may be due to the significantly decreased PS and consequently the increased surface area of the nanovesicles resulting in faster drug release. Also, high drug content was found to significantly increase $\mathrm{EE} \%$ and drug loading leading to an increased drug partitioning from the nanovesicles to the release medium. The second effective factor was the interaction-BC with tween $80(+\mathrm{B})$ and low surfactant content $(-\mathrm{C})$. It was reported that at high surfactant concentration, the drug release was low due to formation of rigid micelles [45]. These findings were agreed with Shaji et al. [48] and Gupta et al. [29], who reported that drug release was related to EE and drug loading. In the present study the optimum surfactant concentration for drug release was found to be achieved by using $5 \mathrm{mg}$ tween 80 . This finding is also agreed with Gupta et al. [29], and Kaylani et al. [49], who found that the use of tween 80 as a non-ionic surfactant significantly increased $(\mathrm{p}<.0 .05)$ drug release from the transfersomal suspensions compared with SDC as an ionic surfactant. The possible explanation of the enhancing effect of tween 80 on drug release rate was the large volume of hydrophilic head group consisting of several polyethylene chains [50]. This structure could impede penetration into tails of lipid bilayer of the transfersomes and increased the deformability of the vesicles and consequently, showed highest drug release [50].

The optimized BD-T formulation was F4 concerning EE, particle size and in vitro drug release. This formulation was selected to be prepared as a pharmaceutical gel using 5\% Na CMC to increase the consistency and consequently the contact time on the application site. The prepared BD-T gel exhibited pseudoplastic flow with a thixotropic behavior. The prepared BD-T gel fit equation (12) as reflected by the value of $\mathrm{R}^{2}$. The pseudoplastic flow of BD-T gel was indicated by the in value $(\mathrm{n}<1)$. Thixotropic behavior was required for application of dermatological gel as it increased the contact time between medication and site of application. The release of BD from BD-T gel was best fitted with Higuchi diffusion.

Upon storage of BD-T gel for 6 mo, the drug release from the gel was used as an indication for physical stability. There was the insignificant difference in drug release kinetics (K) at $4{ }^{\circ} \mathrm{C}$ or $25^{\circ} \mathrm{C}$ during 6 mo $(p=0.998)$ indicating a good physical stability of the formulation. The physical stability of the gel may be due to the physical stability of the transfersomal formulation (F4) which was stabilized by both electrical and steric hindrances as discussed previously [42]. As a result, the recommended storage temperatures for the vesicle formulation were $4{ }^{\circ} \mathrm{C}$ and $25^{\circ} \mathrm{C}$. This finding was in agreement with Duangit et al. [26], who recommend $4{ }^{\circ} \mathrm{C}$ and $25^{\circ} \mathrm{C}$ for storage. However, Laxmi et al. [25], Devi et al. [51], found that transfersomal formulations should be stored at a lower temperature to minimize the drug loss and increase the stability of the drug.

The chemical stability was examined by determining drug content. The changes in the percentage of BD content during the six months were statistically insignificant $(p>0.05)$ indicating good chemical stability. Many studies reported good chemical stability at refrigerated condition $\left(4{ }^{\circ} \mathrm{C}\right)$ and at room temperature $\left(25^{\circ} \mathrm{C}\right)[19$, $25,26,29,51,52]$.

The high physical and chemical stability of BD-T gel may be also due to the stability of the transfersomes included in gel 
formulation. The transfersomal formulation was prepared by the thin film hydration method which was reported to be more advantageous in improving the stability of the prepared transfersomal formulations compared with other methods such as vortexing method [22, 45].

Treated patients suffering from localised plaque psoriasis showed insignificant difference regarding age, sex and duration of illness for both groups. The PGA score was used to assess the patient at baseline and after two months of treatment. Group 1 treated with BD-T gel showed significantly higher clinical effects, safety and tolerability compared with Group 2 treated with BD cream. [45, 53].

\section{CONCLUSION}

The use of BD-loaded transfersomes was effective and promising for carrying the drug into deeper layers of the skin. The transfersomal gel was an effective vehicle for applying BD topically in psoriatic lesions. The BD-loaded transfersomal system was more effective, tolerable and save for treatment of psoriasis compared with the marketed product.

\section{CONFLICT OF INTERESTS}

The authors report no conflict of interest

\section{AUTHORS' CONTRIBUTION}

Sanaa El-Gizaway A,C,D,E,F Maha Fadel A,B,D,E, Basma Mourad A,C,D, Fatma El-zahraa Abdelnaby A,B,C,D,E,F,G, A. Study design, B. Data collection, C. Statistical analysis, D. Data interpretation, E. Manuscript preparation, F. Literature search, G. Funds collection

\section{REFERENCES}

1. King Man H. Psoriasis. Hong Kong Med Diary 2010;15:10-4.

2. Schon MP, Boehncke WH. Psoriasis. N Engl J Med 2005; 352:1899-912.

3. Loo CH, Chan YC, Lee KQ, Palanivelu T, Tan WC. Clinical profile, morbidity and outcome of adult patients with psoriasis at a district hospital in Northern Malaysia. Med J Malaysia 2015;70:177-81.

4. Lowes MA, Bowcock AM, Krueger JG. Pathogenesis and therapy of psoriasis. Nature 2007;445:866-73.

5. Menter A, Gottlieb A, Feldman SR, Van Voorhees AS, Leonardi $\mathrm{CL}$, Gordon KB, et al. Guidelines of care for the management of psoriasis and psoriatic arthritis: Section 1. Overview of psoriasis and guidelines of care for the treatment of psoriasis with biologics. J Am Acad Dermatol 2008;58:826-50.

6. Rustin MH. Long-term safety of biologics in the treatment of moderate-to-severe plaque psoriasis: a review of current data. Br J Dermatol 2012;167 Suppl 3:3-11.

7. Pariser DM, Bagel J, Gelfand JM, Korman NJ, Ritchlin CT, Strober $\mathrm{BE}$, et al. National Psoriasis Foundation clinical consensus on disease severity. Arch Dermatol 2007;143:239-42.

8. Baboota S, Alam MS, Sharma S, Sahni JK, Kumar A, Ali J. Nanocarrier-based hydrogel of betamethasone dipropionate and salicylic acid for treatment of psoriasis. Int J Pharm Investig 2011;1:139-47.

9. Suresh PK, Singh P, Saraf S. Novel topical drug carriers as a tool for the treatment of psoriasis: progress and advances. Afr J Pharm Pharmacol 2013;7:138-47.

10. Lin YK, Huang ZR, Zhuo RZ, Fang JY. The combination of calcipotriol and methotrexate in nanostructured lipid carriers for topical delivery. Int J Nanomed 2010;5:117-28.

11. Ali MF, Salah M, Rafea M, Saleh N. Liposomal methotrexate hydrogel for treatment of localized psoriasis: preparation, characterization and laser targeting. Med Sci Monit 2008;14:Pi66-74.

12. Trotta M, Peira E, Carlotti ME, Gallarate M. Deformable liposomes for dermal administration of methotrexate. Int J Pharm 2004;270:119-25.

13. Lakshmi PK, Devi GS, Bhaskaran S, Sacchidanand S. Niosomal methotrexate gel in the treatment of localized psoriasis: phase I and phase II studies. Indian J Dermatol Venereol Leprol 2007;73:157-61.
14. Pal R, Pandey M. Transferosomes: a novel carrier for enhanced dermal delivery of drug. World J Pharma Pharm Sci 2015;4:1816-32.

15. Sultana ASS, Sailaja K. Transferosomes-a novel approach in the design of transdermal drug delivery system. Int J Pharma Chem Res 2015;1:173-8.

16. Nagasamy Venkatesh D, Kalyani K, Tulasi K, Priyanka VS, Ali SA, Kiran H. Transfersomes: a novel technique for transdermal drug delivery. Int J Res Pharm Nano Sci 2014;3:266-76.

17. Ali MF, Salem HF, Abdelmohsen HF, Attia SK. Preparation and clinical evaluation of nano-transferosomes for treatment of erectile dysfunction. Drug Des Dev Ther 2015;9:2431-7.

18. Bangham AD, Standish MM, Watkins JC. Diffusion of univalent ions across the lamellae of swollen phospholipids. J Mol Biol 1965;13:238-52.

19. Jain S, Jain P, Umamaheshwari RB, Jain NK. Transfersomes--a novel vesicular carrier for enhanced transdermal delivery: development, characterization, and performance evaluation. Drug Dev Ind Pharm 2003;29:1013-26.

20. Shazly G, Nawroth T, Langguth P. Comparison of dialysis and dispersion methods for in vitro release determination of drugs from multilamellar liposomes. Dissolut Technol 2008;15:7.

21. Fadel M, Salah M, Samy N, Mona S. Liposomal methylene blue hydrogel for selective photodynamic therapy of acne vulgaris. J Drugs Dermatol 2009;8:983-90.

22. El Zaafarany GM, Awad GA, Holayel SM, Mortada ND. Role of edge activators and surface charge in developing ultradeformable vesicles with enhanced skin delivery. Int J Pharm 2010;397:164-72.

23. Badran M, Shalaby K, Al-Omrani A. Influence of the flexible liposomes on the skin deposition of a hydrophilic model drug carboxyfluorescein: dependency on their composition. Sci World J 2012. http://dx.doi.org/10.1100/2012/134876

24. Zheng WS, Fang XQ, Wang LL, Zhang YJ. Preparation and quality assessment of itraconazole transfersomes. Int J Pharm 2012;436:291-8.

25. Laxmi MV, Zafaruddin MD, Kuchana V. Design and characterization of the transferosomal gel of repaglinide. Int Res J Pharm 2015;6:38-42.

26. Duangjit $\mathrm{S}$, Opanasopit $\mathrm{P}$, Rojanarata $\mathrm{T}$, Ngawhirunpat $\mathrm{T}$. Evaluation of meloxicam-loaded cationic transfersomes as transdermal drug delivery carriers. AAPS PharmSciTech 2013;14:133-40.

27. Kumar R, Rana A, Bala R, Seth N. Formulation and evaluation of elastic liposomes of clotrimazole. Int J Drug Dev Res 2012;4:348-55.

28. Irfan M, Verma S, Ram A. Preparation and characterization of ibuprofen loaded transferosome as a novel carrier for transdermal drug delivery system. Asian J Pharm Clin Res 2012;5:162-5.

29. Gupta A, Aggarwal G, Singla S, Arora R. Transfersomes: a novel vesicular carrier for enhanced transdermal delivery of sertraline: development, characterization, and performance evaluation. Sci Pharm 2012;80:1061-80.

30. Koo J, Tyring S, Werschler WP, Bruce S, Olesen M, Villumsen J, et al. Superior efficacy of calcipotriene and betamethasone dipropionate aerosol foam versus ointment in patients with psoriasis vulgaris-a randomized phase II study. J Dermatolog Treat 2016;27:120-7.

31. Reich K, Zschocke I, Bachelez H, de Jong EM, Gisondi P, Puig L, et al. Efficacy of a fixed combination of calcipotriol/betamethasone dipropionate topical gel in adult patients with mild to moderate psoriasis: blinded interim analysis of a phase IV, multicenter, randomized, controlled, prospective study. J Eur Acad Dermatol Venereol 2015;29:1156-63.

32. Feldman SR, Krueger GG. Psoriasis assessment tools in clinical trials. Ann Rheum Dis 2005;64 Suppl 2:ii65-73.

33. Chi CC, Wang SH. Efficacy and cost-efficacy of biologic therapies for moderate to severe psoriasis: a meta-analysis and costefficacy analysis using the intention-to-treat principle. Biomed Res Int 2014. http://dx.doi.org/10.1155/2014/862851

34. Gulliver W, Lynde C, Dutz JP, Vender RB, Yeung J, Bourcier M, et al. Think beyond the Skin: 2014 Canadian expert opinion paper 
on treating to target in plaque psoriasis. J Cutaneous Med Surg 2015;19:22-7.

35. Robinson A, Kardos M, Kimball AB. Physician global assessment (PGA) and psoriasis area and severity index (PASI): why do both? A systematic analysis of randomized controlled trials of biologic agents for moderate to severe plaque psoriasis. J Am Acad Dermatol 2012;66:369-75.

36. Tung IC. Rheological behaviour of poloxamer 407 aqueous solutions during sol-gel and dehydration processes. Int J Pharm 1994;107:85-90.

37. El-Gizawy SA, Hedaya MA. Comparative brain tissue distribution of camptothecin and topotecan in the rat. Cancer Chemother Pharmacol 1999;43:364-70.

38. Limsuwan T, Amnuaikit T. Development of ethosomes containing mycophenolic acid. Procedia Chem 2012;4:328-35.

39. El Maghraby GM, Williams AC, Barry BW. Oestradiol skin delivery from ultra deformable liposomes: refinement of surfactant concentration. Int J Pharm 2000;196:63-74.

40. Lei W, Yu C, Lin H, Zhou X. Development of tacrolimus-loaded transfersomes for deeper skin penetration enhancement and therapeutic effect improvement in vivo. Asian J Pharm Sci 2013;8:336-45.

41. Abdellatif AA, Abou-Taleb HA. Transfersomal nanoparticles of keratolytic and antibacterial agents for enhanced transdermal delivery. Journal of Nanotechnol Adv Mater 2016;4:19-23.

42. Huang YB, Tsai MJ, Wu PC, Tsai YH, Wu YH, Fang JY. Elastic liposomes as carriers for oral delivery and the brain distribution of (+)-catechin. J Drug Target 2011;19:709-18.

43. Mishra PR, Al Shaal L, Muller RH, Keck CM. Production and characterization of Hesperetin nanosuspensions for dermal delivery. Int J Pharm 2009;371:182-9.

44. Mitri K, Shegokar R, Gohla S, Anselmi C, Muller RH. Lipid nano carriers for dermal delivery of lutein: preparation, characterization, stability and performance. Int J Pharm 2011;414:267-75.
45. Ascenso A, Raposo S, Batista C, Cardoso P, Mendes T, Praca FG et al. Development, characterization, and skin delivery studies of related ultra deformable vesicles: transfersomes, ethosomes, and transethosomes. Int J Nanomed 2015;10:5837-51.

46. Basha M, Abd El-Alim SH, Shamma RN, Awad GE. Design and optimization of surfactant-based nanovesicles for ocular delivery of Clotrimazole. J Liposome Res 2013;23:203-10.

47. Gonzalez-Mira E, Egea MA, Garcia ML, Souto EB. Design and ocular tolerance of flurbiprofen loaded ultrasound-engineered NLC. Colloids Surf B 2010;81:412-21.

48. Shaji J, Lal M. Novel double loaded transferosomes: evidence of superior anti-inflammatory efficacy-a comparative study. Int J Curr Pharm Res 2014;6:16-25.

49. Kalyani V, Babu MK. Transfersomes: novel vesicular carriers for enhanced transdermal drug delivery of candesartan cilexetil. Indian J Res Pharm Biotechnol 2014;2:1405-14

50. Jacob L, Kr A. A review on surfactants as edge activators in ultra deformable vesicles for enhanced skin delivery. Int J Pharm Sci 2013;4:337-44

51. Devi M, Kumar MS, Mahadevan N. Amphotericin-B loaded vesicular systems for the treatment of topical fungal infection. Int J Adv Pharm Res 2011;4:37-46.

52. Habib FS, Fouad EA, Abdel-Rhaman MS, Fathalla D. Liposomes as an ocular delivery system of fluconazole: in vitro studies. Acta Ophthalmol 2010;88:901-4

53. Hua S. Lipid-based nano-delivery systems for skin delivery of drugs and bioactive. Front Pharmacol 2015;6:219.

\section{How to cite this article}

- Sanaa EL-Gizaway, Maha Fadel, Basma Mourad, Fatma ELZahraa Abd Elnaby. Betamethasone dipropionate gel for the treatment of localized plaque psoriasis. Int J Pharm Pharm Sci 2017;9(8):173-182. 